\title{
Healing the Metabolic Rift between Farming and the Eco-system: Challenges Facing Organic Farmers in Canada and in Sweden ${ }^{1}$
}

\author{
Darrell McLaughlin St. Thomas More College \\ Michael Clow St. Thomas University ${ }^{2}$
}

\begin{abstract}
Résumé
Il ya une liste toujours grandissante d'oeuvres académiques et populaires qui, prises dans leur ensemble, soulèvent des questions majeures portant sur l'agriculture industrialisée et le système alimentaire - et tout particulièrement sur leur impact sur l'environnement naturel. Il ya plus d'un siècle, Marx se servait du concept de "faille métabolique" (metabolic rift) pour décrire les problèmes reliés à la soutenabilité écologique et sociale qui résulte de l'industrie et de l'agriculture capitaliste. Dans cet article, nous examinerons à quel point certains membres du mouvement actuel de l'agricutlure organique abordent la "faille métabolique" et l'organisation social changeante de la production alimentaire.
\end{abstract}

\begin{abstract}
There is a growing list of scholarly and popular works which, when taken collectively, raise major concerns about industrialized farming and our present food system, particularly its impact on the natural environment. Over a century ago, Karl Marx used the concept "metabolic rift" to describe problems related to ecological and social sustainability resulting from capitalist industry and agriculture. In this paper, we examine the extent to which some members of today's organic farming movement are addressing the metabolic rift and changing the social organization of food production.
\end{abstract}

\footnotetext{
${ }^{1}$ Earlier versions of this paper were presented at the 2003 annual meeting of the Canadian Sociology and Anthropology Association, Dalhousie University, Halifax, N.S. and the First Social Research in Organic Agriculture Conference in conjunction with the 23rd Annual Canadian Organic Agriculture Conference, University of Guelph, 2004.

${ }^{2}$ The authors would like to thank Dr. Heidi Epstein and Dr. Ron Griffin, St. Thomas More College, University of Saskatchewan, and Daniel DeLury, University of Saskatchewan, for their conceptual and editorial suggestions. We also thank the anonymous reviewers of this journal for their comments on this paper.
} 


\section{Introduction}

The links between the social organization of food production and environmental problems are becoming increasingly recognized (Beus and Dunlap, 1990; Gertler, 1992). This acknowledgment has led some people to call for the development of alternative approaches to farming (Beus and Dunlap, 1990; Buttel, 1993; Chiappe and Flora, 1998; Clow, 2001; Gertler, 1992; Hill, 1985; Howard, 1940; Jackson, 1997; MacRae et al., 1990; Shiva, 1991; Vail et al., 1994). In this paper we draw attention to the interconnectedness of the environmental impact of agriculture and the food system and their cultural and structural roots. We begin by summarizing some of the main characteristics of capitalist industrial agriculture that we argue are at the heart of many of today's environmental problems. That said, however, the origins of agro-environmental problems lie within thousands of years of history. An analysis of the evidence from our past can help us understand how and why humans developed farming practices; often degrading the natural environment while doing so, the end result rendered the livelihoods food producers insecure. We then constructively engage the concept "metabolic rift", a concept used by one of industrial agriculture's first critics, Karl Marx, appraising current practices of some organic farmers that seemingly respond to concerns raised by Marx over a century ago. We conclude, however, that while farmers have some control over their on-farm practices, the social relations surrounding farming play a dominant role in shaping farming practices and must also change if the interaction between society and nature is to be less destructive ${ }^{3}$. Our research question can be stated as follows: What is at the source of the metabolic rift between farming and nature?; What strategies and practices can be used to heal the rift?; and What factors are inhibiting the healing? The objective in posing these questions are threefold: (1) to contribute to a discussion about theoretical criteria for evaluating sustainability in agriculture and the food system; (2) to make explicit the origins of many of today's unsustainable practices; and (3) to identify more explicitly the location of organic food production in a socio-economic context presently dominated by capitalist institutions.

\section{Dominant Features of Modern Agriculture and the Metabolic Rift}

Modern intensive agriculture has been examined by a number of social scientists (Epp and Whitson, 2001; Goodman and Redclift, 1991; Kloppenburg, 1988; Lawrence, 1990; Mann and Dickinson, 1978; Mooney, 1988; Murphy, 1990; Vail et al., 1994). Many of their

\footnotetext{
${ }^{3}$ Sociologists have struggled with the task of conceptualizing the relationship between nature and society for mainly two reasons. First, nature and society become reified which cause people to lose sight of the how their understanding of nature and society is socially constructed and changes over time. With this change comes differences in the interaction between nature and society but these differences have remained invisible. Secondly, sociologists have tended to resolve the naturenurture debate by claiming that social life and human nature are socially constructed. As science, technology, and industrial development appeared to widen the gap between society and nature, some began to think in terms of humans as being exempt from the constraints of nature that limit other forms of life on earth (Dunlap, 2001). Environmental problems of the 1970s initiated a change in outlook. As Mies and Shiva point out, many scientists are becoming increasingly aware of human's "organic connection with Nature's symbioses" (1993: 156). Our conceptual understanding of the
} 


\section{Healing the Metabolic Rift between Farming and the Eco-system: Challenges Facing Organic Farmers in Canada and in Sweden}

studies describe a system of production that increasingly displays characteristics similar to those currently found in the industrial manufacturing sector. The main features of today's intensive agricultural system include a: growing concentration of productive assets (Goodman and Redclift, 1991; Vail et al., 1994); the substitution of capital for labour (Vail et al., 1994); the increasing separation of manual labour from managerial control as farm units grow larger (Mooney, 1988); the escalating costs of farming that restricts the entry of young farmers (Mooney, 1988; and Lawrence, 1990); the genetic manipulation of nature (Goodman and Redclift, 1991; Kloppenburg, 1988); and the application of the principles of industry (Mann and Dickinson, 1978; Murphy, 1990).

Clow (2001) argues that we can only adequately understand the impact agriculture has on the environment if we recognize that all forms of farming require human efforts to create and sustain artificial ecosystems (agricultural ecosystems). Stated otherwise, agricultural ecosystems are unstable because natural ecosystems are continually re-establishing diversity, and the human-subjugation of the natural ecosystem is accomplished at a high cost that entails: dependence on industrial inputs, pest and disease resistance, loss of biological diversity, and water and wind erosion ${ }^{4}$.

The above literature makes evident that the primary cause of environmental problems is social. Environmental problems in agriculture occur when humans increase production beyond what nature can sustain within a specific cultural period ${ }^{5}$. Capitalism ${ }^{6}$ is the dominant form of social relations of production that characterizes the current period. Capitalists have become successful because of their single obsession with economic expansion to accumulate material wealth with total disregard for the social and environmental impacts of their actions. They cannot voluntarily accommodate the increasing costs that ecological sustainability requires without abandoning the project which is their defining 'raison d'etre' (Clow, 2001: 5). We will return to the contradiction between capitalism and nature later in our discussion of Marx's views on the reasons capitalist social relations represent a barrier to ecological sustainability. First, however, it would be constructive to document the antecedents of such negative dynamics between human and nature for it is by no mean

relationship between society and nature has been influenced by Dunlap's and Catton's (1994) "new ecological paradigm (NEP)" and feminists' insight that "[N]ature has a value that cannot be reduced to its usefulness to culture...." (Tong, 1998: 260). Although culture and other social creations appear to illustrate human uniqueness, humans share with all life an interdependence with the web of nature. While human culture can extend the carrying capacity of ecosystems, there are ecological laws, many of which humans remain unaware.

${ }^{4}$ Damage from wind and water erosion occurs more frequently when fields are made larger to accommodate bigger machinery and or natural vegetation is destroyed.

${ }^{5}$ In this paper, our conceptual understanding of the relationship between society and nature has been influenced by Dunlap's and Catton's "new ecological paradigm (NEP)" (Dunlap, 2001: 56).

${ }^{6}$ In its purest form, capitalism is a socio-economic system in which the means of production are privately owned and controlled by capitalists. Labour used in the production process is provided by workers in exchange for wages. Profits generated from the sale of goods and services belong to the capitalists. 


\section{Healing the Metabolic Rift between Farming and the Eco-system: \\ Challenges Facing Organic Farmers in Canada and in Sweden}

unique to our modern period. Looking back, we can find scientific evidence that can assist us as we make choices about options for our future.

\section{The Metabolic Rift}

The growing estrangement between nature and human culture began thousands of years ago (Cohen, 1977; Diamond, 2005; Ponting, 1991; Redman, 2004; Tainter, 1988; Wright, 2004). Sociologists have argued that our dependence on culture for survival has increased in direct proportion to a decline in our awareness of nature (Dunlap, 2001; Eder, 1996; Murphy, 1994). The decreased awareness of the natural environment is linked in turn to social and geographic distancing (Redman, 2004). Social distancing refers to the ways the formation of social hierarchy influences the relative legitimacy and value of a certain group's knowledge and power over others (men, rulers, priests, landlords, managers, shareholders versus that of women, peasants, slaves, workers, farmers). Geographic distancing consists of the ways in which larger societies and eventually civilizations distribute their ecological footprint $^{7}$ across many ecosystems (Wright, 2004). Through a "social pyramid system", wealth is gathered to the centre while the ecological consequences are distributed over a larger geographic area and made invisible by those with economic and political power (Wright 2004: 83-84). As a result of such diffusions, people at the centre of empires were not able to see the consequences of their exploitation directly, both on the natural environment and on other people.

Not surprisingly then, given these entwined "distancings," and the global reach of Western "civilization," cultural ignorance of the processes of nature has increased, particularly as they relate to farming. Moreover, further efforts are being made to control these processes through the application of science and new forms of social organization. For example, science has been used to produce more sophisticated agricultural ecosystems by employing chemical pesticides, fertilizers, and irrigation technology. New forms of social organization related to the production and distribution of food are also having an impact on the natural environment, more specifically those social relations related to capitalist globalization. To reverse cultural ignorance and foster more sustainable ecosystems, we need to understand the intended and unintended consequences of our ancestors' farming practices, especially those linked to the rise of both industrialization and capitalism itself.

In the 19th century, Karl Marx raised trenchant criticisms of industrial agriculture. Foster (2001) summarizes Marx's outline and critique of the major events in the historical development of agriculture and their environmental consequence. With the first agricultural revolution came the process of removing people from the land (the Enclosure Movement). Placing people in towns and cities reduced recycling of human organic waste back to the

\footnotetext{
${ }^{7}$ The concept of "ecological footprint" refers to the area of the earth needed by a specific group of people to produce the resources to sustain their lifestyle and absorb their waste (Wackernagel and Rees, 1996).
} 


\section{Healing the Metabolic Rift between Farming and the Eco-system: Challenges Facing Organic Farmers in Canada and in Sweden}

soil and increased the net loss of soil fertility ${ }^{8}$. The development and use of chemical fertilizers -- the technological changes associated with the second agricultural revolution (1830-1880) -- was intended to compensate for this deficit in recycled nutrients. The third agricultural revolution was identified with the increased use of mechanical traction and technology to replace animal and human power. As animal production thus became limited mainly to feedlots, fewer forages, particularly legumes, were fed to ruminant animals. As the amount of forages decreased there was a corresponding increase in the amount of grains used in animal rations. Additionally, feedlot operators often did not have an adequate land base on which to dispose of the manure. Because nitrogen-fixing legumes were not widely grown, chemical sources of nitrogen were increasingly employed but without the additional benefits of organic matter and related microbial activity (Lotter, 2003: 60). This created a dependence upon industrially produced chemical fertilizers. Consequently, money flowed off-the-farm to head offices in urban centres (and in many cases to other countries), leaving farmers more financially vulnerable.

All of these developments generated what Marx diagnosed as a metabolic rift, the general elements of which can be summarized as follows: The alienation between nature and society is the result of disruptions in nature caused by the interaction between the social organization of food production and the processes of nature. Industrial agricultural systems are designed to provide both cheap foods for the population of industrial centres as well as the accumulation of capital for owners of the various means of production. The linear movement of nutrients from rural to urban areas (outlined above) degrades soil fertility in the country and simultaneously adds to the massive build up of household waste in cities. Finding solutions to the rift is made difficult for two reasons. First, rural-urban relations among the populace are antagonistic. The urban population wants, and in some cases demands, that food be as cheap as possible. This is also in business owners' interest for whom cheap food means less capital will go to maintaining workers, thereby allowing more to be directed towards manufactured goods and to owners' profits. The greater political and economic power of the urban population ensures that ecological damage will continue rather than become seen as counter-productive. According to Marx and Engels, the ecological damage in rural areas does not "abolish this antithesis, capitalist society on the contrary is compelled to intensify it day by day" because of the power of the urban population (quoted in Burkett, 1999: 119). Second, large-scale capitalist agriculture actually discourages the consistent rational application of scientific knowledge to the problems of soil management and the essential cycling of soil nutrients. Instead, people only become interested in soil fertility after its natural qualities have been depleted and once the problem is perceived as critical, it will only be addressed provided the cost of the solution is not prohibitive 9 . Marx writes, “...the entire spirit of capitalist production,

${ }^{8}$ The removal of people from the land in the British Isles took the form of the "Bills for Inclosure of Commons" in 1799. For a discussion of some of the impacts of the enclosure movement see Marx (1977: 885-890).

${ }^{9}$ The International Food Policy Research Institute identifies the six main forms of land degradation: 
which is oriented towards the most immediate monetary profit - stands in contradiction to agriculture, which has to concern itself with the whole gamut of permanent conditions of life required by the chain of successive generations" (quoted in Foster, 2001: 77) ${ }^{10}$.

A Marxian metabolic rift is also evident at the international level where soil nutrients of colonies and developing nations are transferred to support the industrialization of other countries. For example, throughout history, Canada has exported staples, first to England, then to the United States, and now to other economic centres (Albrow, 2001; Innis, 1930; Marchak, 1985). The result has been a continual exodus of goods and nutrients from Canada. It is precisely because the process has been going on from before confederation that many Canadians assume that such an economy is a priori, and therefore without viable alternatives (Laxer, 1988). Most Canadians are unaware that our soils are managed unsustainably.

To understand the full extent to which today's efforts to establish a sustainable agriculture addresses Marx's earlier theoretical projections of a metabolic rift, we must now trace the commercial path of food items back from the retail and wholesale outlets, through the processing and transportation system to the site of actual production - the farm. The practices and social relations at the level of farms are the foundation of the food system. For in this mapping we may discover to what degree the people involved with the development of sustainable agriculture are conscious of the metabolic rift, and are making specific efforts to address it.

\section{Sustainable agriculture and the Metabolic Rift}

The term "sustainable agriculture" is used, often loosely, to describe the goals of farmers, farm organizations, government policy makers and even appears in agri-business promotional material. Within this paper, the term situates food production within a specific ecological, economic, and social reality such that farmers, consumers and corporations ethically respond in context appropriate ways (MacRae et al., 1993). Based on this context-specific definition, in theory, sustainable agriculture should address many of the issues raised in our earlier discussion of Marx's work. We have chosen to study the practices of organic farmers as an example of sustainable farming not because their practices are environmentally and socially permanent in any absolute sense but because

\footnotetext{
loss of soil nutrients, salinisation, agrochemical pollution, soil erosion, overgrazing, and deforestation. "Nearly two-fifths of all farmland has been subject to some degree of degradation since the middle of the twentieth century, accounting for a $17 \%$ loss in productivity over that period - even though this has been balanced in some measure by improvements in land quality and conversion of some forest, range, and pasture to agriculture" (McLaughlin, 2002: 13).

${ }^{10}$ Understanding what Marx means by large-scale agriculture in relation to the metabolic rift poses a problem for us today. By 1870s standards, even today's small farms are large. But more importantly, except in the case of subsistence production, small farms are also surrounded by and embedded in capitalist social relations and their products are likely to be shipped to distant markets (Lyson, 2004).
} 


\section{Healing the Metabolic Rift between Farming and the Eco-system: Challenges Facing Organic Farmers in Canada and in Sweden}

organic farmers appear ready to reflect critically and continually on the environmental and social consequences of their farming methods. Organic farmers carefully plan their production processes with the goal to manage a diversified, self-balancing agricultural eco-system (Clow, 2001).

\section{Method}

The following analysis involves a re-examination of data first collected by McLaughlin (2000) as part of an ethnographic study of the development of sustainable agriculture in Canada and in Sweden ${ }^{11}$. In it, we explore the extent to which organic farmers' actions and views were (and are) concerned about and affected by nutrient cycling, energy consumption, water usage, the antagonism between rural and urban people, and the reasoned practical application of science, in other words the metabolic rift.

Data for both Sweden and Canada were gathered from extant studies, government documents, meetings of organic and conventional farmers, conferences on organic production practices, federal government meetings, and an actual on-farm research group. However, it should be noted that the data do not include primary information about consumer behaviour. The primary data consist of the accounts of the people interviewed using intensive interviewing techniques. These interviews were guided by open-ended questions using an institutional ethnographic methodology (Smith, 1987). Questions asked were divided into four general categories: people's farming activities, technologies used, their flow of capital, and their attitudes and relationships to state policies and other institutions. In total, 45 farmers, farm leaders, food activists, academics and government officials were interviewed ${ }^{12}$.

Interview candidates were chosen on the basis of their evident access to first-hand information either within a relevant organization or their actual farming experience. In Canada, a list of possible interviewees was generated through personal contacts and snowballing ${ }^{13}$. In Sweden, contacts were arranged via the ecological farmers' organization, Ekologiska Lantbrukarna. Whenever possible, farm people were interviewed on their farms. Interviews were conducted between January and December of 1996 and they lasted

\footnotetext{
${ }^{11}$ Funding for the original data collection was provided through a doctoral fellowship grant from the Social Sciences and Humanities Research Council of Canada and the Nels Anderson fund at the University of New Brunswick.

${ }^{12}$ People interviewed can be divided in the following manner: 20 people in Sweden - 12 organic farmers; 2 leaders in farmer's organizations; two representatives of the Board of Agriculture; 1 representative of a certifying body; 3 Swedish academics; 25 people in Canada - 12 organic farmers; 2 leaders in farmers organizations; 4 representatives of governments; 2 people with certifying bodies; 3 Canadian academics; 2 representatives of food or environmental related organizations.

13 'Snowballing' is a sampling technique which involves beginning with one or two contacts and asking them for names of people that might have important information about the topic. This process is repeated with the new contacts until an adequate sample is generated. A sample generated through 'snowballing' was particularly useful in the case of research on organic farmers because many of the informants are not known by, or easily accessible to, people outside of the organic movement.
} 
on average, one and one half hours but ranged between one and four hours.

\section{Findings and Analysis}

To determine whether or not those interviewed attend to our current variation on Marx's metabolic rift, we must first examine what organic farmers use as indicators of balancing human activities and natural processes, and then evaluate the socio-economic context in which organic farmers find themselves. We will then consider how capitalism influences the activities of experts within this wider context, more precisely, scientists, academics, government agencies, and consumers, assessing whether all of the above facilitate or impede farming practices that could reduce the rift between nature and society.

\section{(i) Water, Nutrients, and Energy Circulation}

(a) Indicators of Balance

One of the defining features of organic farming is its practitioners' greater sensitivity to the natural environment. The organic farmers interviewed explained that their knowledge about nature emerges from a more general concern for health: the health of the soil, of plants, of animals, and of human beings. In their view, the health of the entire food and eco-systems hinges on the texture, fertility, and biological activities in the soil. Organic farmers describe soil fertility as balancing nutrients and energy flows within the context of the local agro-ecological system. One Swedish dairy farmer stated, "If all the energy [and nutrients are] going to circulate, [then the different aspects of the farm operation] have to fit, the number of animals and farm area .... Finding the balance is difficult because we are not an area that grows a lot of grain." The point that this farmer is making is that organic standards restrict the number of animals that can be housed in a specific area. Supplies of feed can also be a constraint since their feed must also be organic. Other farmers' comments indicate sensitivity to the conditions of wildlife on and around the farm, especially earthworms and birds. One vegetable farmer speculated that the increasing numbers of birds that he sees on his land is the result of no longer using chemical pesticides, and of introducing winter cover crops into his rotation. Beyond these technical alternatives, nearly all the Swedish farm interviewees made broader interconnections between farming practices and human health, having noted particularly the rise of allergies in children and increases in the number of cases of antibiotic resistant bacteria. Also Swedish livestock farmers interviewed expressed a desire to try to find ethical and humane methods to produce meat and other livestock products due to either their own personal convictions, or to social pressures or regulations. Similar relationships and concerns were expressed by Canadian organic farmers but not with the same intensity.

(b) Energy Consumption

Energy consumption in food production is currently receiving greater attention in Canada 


\section{Healing the Metabolic Rift between Farming and the Eco-system: Challenges Facing Organic Farmers in Canada and in Sweden}

in light of concerns about global warming and the Kyoto Protocol. On average, for every unit of food energy produced, 10 units are consumed in its production, processing, and transportation. Debate about the role energy consumption and sources should play in organic food production is only beginning to take place. A summary of a study conducted by the Swedish cooperative Konsum (Sundas, 1996), compared locally produced food to that of imported food products on the basis of energy consumption (kilometres travelled) and pollution emissions. The authors concluded that, generally speaking, the higher energy cost incurred by importing food has a very high environmental impact compared to locally grown organic food. This discussion about the environmental consequences of consumers' choices has in turn stimulated a debate about the use of energy at the farm level. As one Swedish dairy farmer stated "It is hard for me to tell consumers that my milk is ecological if I am not good in terms of energy [efficiency]."

\section{(c) Urban Sewage}

Conserving nature and energy on the farm also means recognizing that the movement of food to urban centres involves the flow of nutrients, energy, and water. Efforts are being made in both Sweden and Canada to make this circulation safe and efficient. As of 1996, organic farmers could not apply urban sewage to their land because of concerns that it might contain harmful levels of heavy metals, soft plastics, and hormones (particularly estrogens). While organic farmers worry about the contents of such urban sludge, most support the principle of recycling the nutrients. What is lacking is an infrastructure which would provide separation "at source" of the safe from the toxic sewage components as well as monitoring devises for their output. Determining what final composition is safe is no simple task.

During the 1980 s, up to $60 \%$ of Swedish municipal sewage sludge was spread on agricultural land before the effects had been thoroughly investigated. Following an environmental assessment conducted in the early 1990s, the amount that was spread dropped to less than ten percent. The decline was primarily due to farmers' fear of consumers' negative reactions to contamination risks ${ }^{14}$. By the mid-1990s, however, public support for waste recycling had increased and more farmers were once again applying sludge to their fields (Vail et al. 1994: 127). Nevertheless, organic farmers are still not applying urban sludge to their fields because standards for organic production are more stringent. In sum, while they appear to be very aware of the disruptions that farming imposes on nature, the nonrecycled unilateral movement of soil nutrients and the subsidiary build up of urban waste remain aspects of the metabolic rift that organic farmers have not been able to adequately address. We now turn to the further exacerbation of the rift due to the failure to use scientific knowledge rationally under capitalism.

\footnotetext{
${ }^{14}$ Other reasons for the decline in the use of urban sewage sludge were the messiness, the expense of handling a bulky product that contained high levels of water, and the often unpleasant odours which some neighbours may find offensive.
} 


\section{(ii) Capitalism, Science and Soil Management}

\section{(a) Impoverishing the Soil}

Organic agriculture is not developing in a vacuum but rather within a food system dominated by capitalist institutions whose interests reflect and support those of industrial agriculture. During one interview, an employee of a conservation group in Canada provided graphic evidences of the importance of soil health and why it should be a major concern for producers and consumers. Pointing to a map displaying differences in soil degradation worldwide, she noted that North-western New Brunswick was a high-risk region due to its intensive potato production. Similarly, interviews with formerly conventional Canadian farmers who converted to organic farming explained their reasons for switching to organic as being literally 'rooted' in the soil; when it is exhausted, land must be rebuilt through crop rotations and/or the application of soil amenities if it is to regain its vitality. Many of the organic farmers interviewed described the process of revitalizing their farmland as a sophisticated process that acknowledges the uniqueness of each piece of land. We will return to the issue of intimate understanding of natural processes later when we discuss public and private research but first we will examine how market relations are shaping the development of organic farming.

\section{(b) Focus on Markets}

Under capitalism, the focus is on markets, while activities that are less likely to produce immediate and maximum returns are dismissed. One university professor who works with organic farmers cautiously explains how capitalism shapes farming practices."There is a propensity for agribusiness to market products.... Some of the things that have a beneficial effect [on the soil] just don't seem to make a lot of money. So, it would seem to me that the way the system is set up right now is that agribusiness seems to be in conflict with sustainable agriculture for the most part." One vegetable farmer was more direct in his critique of the impact of capitalist relations on farming practices. He uses the term "polarization" to describe the divergence between industrial agriculture and sustainable farming practices. He then offers the insight that it is not just farming practices but also the social relations surrounding those practices that influences sustainability. In his words, "[T]he organic movement, in as far as it aligns itself with the...large scale production and the wholesale route and dependence on transportation and technology...is not really sustainable." In his view, the industrial food system and organic farming are not compatible. His comments reveal tensions and contradictions emanating from within the sustainable agriculture movement. His views are similar to Altieri's position (2000: 88-89) that organic farmers who focus exclusively on input substitution and production standards to comply with organic regulations while ignoring monoculture and capitalist relations in agriculture will fail to see the socio-structural source of environmental degradation in farming. 


\section{Healing the Metabolic Rift between Farming and the Eco-system: Challenges Facing Organic Farmers in Canada and in Sweden}

(c) Research: Private vs Public

Private Research

The future of organic farming and the healing of the current metabolic rift are jeopardized by national and international research trends. Cuts to public funding for research have produced an opportunity for private companies to increase their influence over the future direction of agricultural development (Wolf and Wood, 1997). One Ontario farmer interviewed described how he sees agricultural research and technologies, and resultant changes in farming practices, becoming tightly interwoven with the capitalist drive to commodify. In his words, "The whole ethic of agriculture in North America is designed around this idea that it is not really a useful solution unless somebody is going to buy and sell it, and consequently the whole notion of indigenous knowledge, the wisdom that accumulates from years on the land, is devalued." To the extent that researchers are focussing on optimizing both market conditions and food production rather than providing solutions to soil problems, they will ironically prevent the rational application of science as one vital means of healing the metabolic rift.

\section{Public Research}

Conversely, the more holistic ethos and soil management practices of organic farmers are not forms of information that are easily "packaged" for sale (Northwest Area Foundation, 1994). For example, organic farmers strive to reduce the use of purchased inputs through ecological practices such as natural fertilizers, complex crop rotations, diversified crops and livestock production, and integrated pest management. These practices contrast dramatically with the commodified knowledge that corporations gather and regard as valuable, for example the traits that give genetically modified canola tolerance to a specific herbicide. Here even the means of knowledge acquisition diverge; organic farmers have collectively amassed information through personal experiences and literature. ${ }^{15}$ This information moreover is often exchanged freely and willingly amongst groups of farmers. In spite of its potential benefits, non-commodified knowledge receives low levels of private industrial investment because it is associated with "unshielded" practices (Wolf and Wood, 1997: 193). ${ }^{16}$ The use of unshielded technologies reduces the flow of capital from the farm, and hence, is antithetical to capitalist industrialism. As a result sustainable agriculture becomes even more dependent on publicly funded research if scientific knowledge of the same is to be generated. ${ }^{17}$

A detailed discussion of the role of the state in sponsoring public research is beyond the scope of this paper. However, it must be noted that political opposition to many of the practices associated with conventional agriculture is much greater in Sweden (ie. ethical

\footnotetext{
15 James Scott (1998: 303) describes the mixture of practical and scientific knowledge as Métis knowledge.

16 "Unshielded" means that the ownership and use of a particular knowledge is not restricted by intellectual property rights laws.

${ }^{17}$ The Organic Agriculture Centre of Canada was founded in 2000 to promote and coordinate research and facilitate farmers' transition to organic farming.
} 
treatment of animals, health issues, and the general conservation of nature). This political opposition has been translated into state support for environmentally sensitive practices by the Swedish state and the European Union. There is mounting pressure to change the role of states in agriculture both in Europe and North America (Flora, 1990). This pressure comes mainly from two very different types of critics: those critical of government funding of industrial farming for environmental reasons and those wanting to liberalize trade and "freeing market forces". In Sweden, organic farmers are considered more politically acceptable for receiving state support because their practices are viewed as a means of moving all of agriculture (research, food production, and marketing) towards greater collective environmental sensitivity and better stewardship of rural landscapes. There are also important trends taking shape in Canada, although not on the same scale as is found in Sweden. For example, the Organic Agriculture Centre of Canada operates offices in both Truro, Nova Scotia and in Saskatoon, Saskatchewan and is encouraging research on a range of topics (2007). It must be emphasized, however, that regardless of reforms in public/private research funding, the state's ability to initiate and institutionalize and change is slow and complex compared to the means that consumers have of collectively galvanizing ecologically-informed change at the level of households.

\section{(iii) Consumers and Healing the Rift}

Consumer organizations have the potential to wield great power. However, these groups often suffer a kind of metaphorical "Attention Deficit Disorder" as they appear unable to focus on a single issue for very long (Magdoff et al., 2000). Nonetheless, one Swedish farmer stated that he believes the power for change lies in the hands of consumers. $\mathrm{He}$ stated, "You provide the information to the consumers and if they say "we don't want this' there is nothing the state can do. Also the big companies will follow the consumers; they will change their production too." ${ }^{18}$ Contrary to what one frequently hears about the tensions between producers and consumers - that producers always ask too much for their product or that consumers are just interested in cheap food - we did not find evidence of strained relations between organic farmers and their consumers. Although we do not have data on consumer attitudes towards organic farmers, the farmers interviewed described ways in which they found consumers to be supportive. One might speculate that this support is due, in part, to consumers of organic products sharing many of the same environmental and health related objectives as organic farmers. We did find that, during the early stage of the development of organic farming within a particular locale, there tends to be more direct contact between farmers and consumers. Consumers either obtain farm products on-the-farm, at farmers' markets (the most common way in Canada), or through consumers' clubs. Although none of the farm people interviewed were participants in Community Supported Agriculture (CSA) groups, a couple of farmers did suggest that these kinds of groups were effective ways for consumers to remain informed and involved

\footnotetext{
${ }^{18}$ The current debate over the legislative labeling of genetically modified foods exemplifies how crucial some companies like Monsanto consider controlling information available to consumers.
} 


\section{Healing the Metabolic Rift between Farming and the Eco-system: Challenges Facing Organic Farmers in Canada and in Sweden}

in meeting their ecologically- guided food needs.

One Ontario farmer also described an additional impediment to constructive producerconsumer dialogue, namely, conventional marketing channels themselves. These channels do not allow producers and consumers to know one another. In his words, "Because we are so distanced from the people we service, we are cut off by the process and the people in between. We are robbed of the recognition that should be ours as producers of food." Unfortunately, the vast majority of farmers simply are not in close proximity to large urban centres to physically sustain such dialogue. Additionally, major supermarket chain stores are now offering certified organic products for sale. This means that producers and consumers are going to have to be imaginative and deliberate in finding ways to "know" one another's situation and needs in spite of geography and the middleman. One possibility that was suggested during an interview is the creation of organic food cyberterminals around which virtual communities might form.

Such distancing, both physical and social, between producers and consumers has been increasing little by little since the beginning of farming (Wright; 2004). Much of the conventional food system is now global. Globalization works through the practices of individuals and institutions that transgress national boundaries on a daily basis (Giddens, 1990). Producer-consumer dynamics now entwine a complex web of households, communities, nation-states, and trans-nationals. These long distance interactions have been made possible primarily by technological changes in communication and transportation. A Saskatchewan organic farmer offers an analysis of how globalization and world trade delays the rational application of science under industrial capitalist agriculture to the problem of soil management discussed above. She explains, “....the transnationals... do not suffer immediately from the loss of ecological balance, from the environmental degradation because they are mobile and they move elsewhere". Given such corporate, market-driven indifference, this farmer concludes that sustainability will require actions and changes within corporate, legislative, and individual ethos, as well as social structural changes. The structural change she describes appear to us as the need to create economies of sufficiency as opposed those based on producing and consuming to maximum capacity (Wackernagel and Rees, 1996).

\section{Conclusion}

Admittedly, the sample on which we base our findings and analysis is limited. And yet, the cases of organic agriculture in Canada and in Sweden do persuasively illustrate that the ability of farmers to begin healing the rift between society and nature is either constrained or facilitated by the wider social context in which their own knowledge and ideological framework is formed. In spite of Canadian and Swedish farmers' common desires and concerns about the environmental consequences of conventional industrial agriculture, the 
social relations surrounding the development of sustainable agriculture in Sweden enable farmers there to move more readily into organic farming than those in Canada - Swedish organic farmers have more consumer support and benefit from political policies to fund the stewardship of rural landscapes. However, despite such localised progress, healing the metabolic rift, identified over a century ago by Karl Marx, remains largely unaddressed - both in Canada and in Sweden. The recycling of soil nutrients, reducing the antagonism between town and country, and eliminating the barriers to the rational application of science to soil management still requires more substantial changes in the social relations at many different points in the food system and urban planning within both countries. To be sustainable, socio-economic systems must be ecologically sound and socially just in terms of the distribution of costs and benefits, not only for present but also for future generations. Many members of the sustainable agriculture movement appear to be aware of some of the negative social and ecological consequences related to industrial farming. Less evidence exists to suggest that there is a more widely shared awareness let alone analysis of the consequences of capitalism. Agriculture producers alone cannot heal the metabolic rift that has been literally thousands of years in the making. The tendency to diminish the impact of social, political, economic, and scientific practices to a narrow set of financial indicators (the most prominent is the return to shareholders), as a hegemonic trend, is a form of reductionism that is having nothing less than catastrophic effects. Better informed consumer/activist demands for structural reform may impede current industrial reductionist approaches. Cultures may develop both locally and globally, that have the capacity to recognize the consequences of our individual and collective actions and take responsibility for them. In the meantime, as we work to create this ecological age, all consumers must: buy locally products which have been produce using sustainable practices, compost and recycle waste to reduce our ecological footprint. Both organic farmers and consumers interested and committed to a sustainable agricultural system must consider their willingness to change the social relations within which they live. New social relations will be required to escape the demand upon their every action to contribute to capital accumulation. They must imagine and create a form of social organization in which to live that would prioritize human need, not capital accumulation, and also to prioritize the needs of the environment, whether out of ethical concern for Nature and/or human self interest. In other words, farming may have to escape being embedded in petit-production as well as in capitalist production per se and consumers as well have to understand the capitalist social system as the structural basis of the problem.

Obviously, conclusions drawn from 45 interviews across two countries can hardly be the basis for detailed generalizations about the actions and attitudes of organic farmers. Nevertheless, we do believe that we have identified some general and telling patterns, many of which warrant further investigation. The development of sustainable agriculture is being influenced by diverse agents of social change, including farmers and peasants 


\section{Healing the Metabolic Rift between Farming and the Eco-system: Challenges Facing Organic Farmers in Canada and in Sweden}

and their organizations, migrant farm workers, consumers, processors, government policy makers, scientists and a variety of activists -- health, environmental and animal rights. Sociologists argue that people's ability to imagine and create alternative political, economic and cultural values and world views is influenced by the relative strength of the hegemonic forces present in a social setting at a specific point in time. The extent to which today's organic agriculture will contribute to and one day become part of a sustainable food system will depend on people's willingness and ability to reflect critically on their beliefs and actions and make adjustments. People's ability to act differently and to reform unjust and ecological destructive practices - their agency - is further dependent on the availability of resources (social, natural, intellectual, political, and financial) and their willingness to consider alternatives. Thus, if sustainable agriculture is to develop to the point where it can heal the rift between the eco-system and farming, the first step lies in enthusiastically promoting and sustaining a much wider discussion about the current food system. ${ }^{19}$ Once its members learn from, and are guided by evidence from history and an analysis of current events, a society develops the dialectical ability to be self critical and self-transformative.

As academics and social scientists, we have an important role to play. We need to make explicit the intended and unintended consequences of both consumer and corporate practices, i.e. globalised hyper-capitalist food production, and offer informed opinions on alternative economic, rationally scientific and government supported options as we exert efforts thereby toward the long term goal of healing the metabolic rift that has been a recessive feature of most human cultures, in one form or another, since the beginning of agriculture.

In short, the ecological 'bottom line': “...[T]he health of land and water - and of woods, which are the keepers of water - can be the only lasting bases for any civilization's survival and success" (Wright, 2004: 104). If we do not find ways to balance culture and nature, both society and the eco-system become irreversibly impoverished because of our failures. In the past, our ecological footprint was small enough that our inattentiveness to the longterm consequences of our cultural practices limited damage to ourselves, isolated cultures, and to our immediate environment rather than to the entire planet and all of humanity. Now the stakes are much higher.

The above argument suggests two conclusions. First, Marx's agricultural prognosis continues to be relevant for understanding today's alternative and mainstream methods of food production and consumption. Second, further research questions related to the social dynamics surrounding organic farming merit exploration. Recent successes in the cultivation and marketing of organic farm products have precipitated qualitative and quantitative changes in farming. We need to record how organic farmers' actions and

\footnotetext{
${ }^{19}$ Magdoff et al (2000: 18) make the argument that as organic farmers shift from niche to mainstream markets, they will experience increasing pressure as agribusiness and giant food retailers (for example, Sobeys, Loblaws and Walmart) target the more profitable products and markets.
} 
choices are being shaped. And finally, there are questions about the social consequences of organic agriculture for rural communities (the impact of organic farming practices on the social relations of the farm household, the input sector - including farm workers, the output sector - the chain of relations between the farm and consumers, and the rural community). Answers to questions like these will greatly assist and direct people's efforts - legislative, productive, and consumptive - to heal the metabolic rift. 


\section{Healing the Metabolic Rift between Farming and the Eco-system: \\ Challenges Facing Organic Farmers in Canada and in Sweden}

\section{REFERENCES}

Albrow, M. 2001. “Globalization.” In New Society: Sociology for the 21st century (3rd Ed.). R. Brym (ed.) Toronto: Harcourt Canada, pp. 423-448.

Altieri, M. A. 2000. "Ecological Impacts of Industrial Agriculture and the Possibility for the Truly Continuing Relevance of Sustainable Farming." In Hungry for Profit: The Agribusiness Threat to Farmers, Food, and the Environment. F. Magdoff, J. Bellamy Foster and F. Buttel (eds.). New York: Monthly Review, pp. 77-92.

Beus, C. and R. Dunlap. 1990. "Conventional versus Alternative Agriculture: The Paradigmatic Roots of the Debate." Rural Sociology, Vol. 55, No. 4, pp. 590-616.

Burkett, P. 1999. Marx and Nature: A Red Green Perspective. New York: St Martin's Press.

Buttel, F. 1993. "The Sociology of Agricultural Sustainability: Some Observations on the Future of Sustainable Agriculture." Agriculture Ecosystems and Environment, Vol. 43, pp. 175-186.

Chiappe, M. and C. Flora. 1998. "Gendered Elements of the Alternative Agriculture Paradigm.” Rural Sociology, Vol. 63, No. 3, pp. 375-393.

Clow, M. 2001. "Why Environmental Problems are Endemic to 'Agriculture' in all its Branches". Unpublished presentation to Rural Issues Conference, University of Guelph, Guelph, Ontario.

Cohen, M. 1977. The Food Crisis in Prehistory: Overpopulation and the Origins of Agriculture. New Haven: Yale University Press.

Diamond, J. 2005. Collapse: How Societies Choose to Fail or Succeed. Toronto: Penguin Group.

Dunlap, R. 2001. "The Evolution of Environmental Sociology: A Brief History and Assessment of the American Experience." In The Environment and Society: Reader. R.S. Fry (ed.). Boston: Allyn and Bacon, pp. 43- 62.

Eder,K.1996.The Social Construction of Nature: A Sociology of EcologicalEnlightenment. Thousand Oaks, California: Sage Publications. 
Epp, R. and D. Whitson. 2001. "Introduction: Writing off Rural Communities." In Writing off the Rural West: Globalization, Government, and Transformation of Rural Communities. R. Epp and D. Whitson (eds.). Edmonton: University of Alberta Press, pp. xiii-xxxv.

Flora, C. B. 1990. "Presidential Address: Rural Peoples in a Global Economy." Rural Sociology, Vol. 55, No. 1, pp. 157-177.

Foster, J. B. 2001. "Marx's Theory of the Metabolic Rift: Classical Foundations for Environmental Sociology" In The Environment and Society: Reader. R.S. Fry (ed.). Boston: Allyn and Bacon, pp. 63-95.

Gertler, M. 1992. “The Social Economy of Agricultural Sustainability.” In Rural Sociology in Canada. D. Hay and G. Basran (eds.). Toronto: Oxford University Press, pp.173-188.

Giddens, A. 1990. The Consequences of Modernity. Stanford, CA: Stanford University Press.

Goodman, D. and M. Redclift. 1991. Refashioning Nature: Food, Ecology and Culture. London: Routledge.

Gramsci, A. 1971. Selections from the Prison Notebook. New York: International Publishers.

Hill, S. 1985. "Redesigning the Food System for Sustainability." Alternatives, Vol. 12, Nos. 3 \& 4, pp. 32-36.

Howard, A. 1940. Agricultural Testament. Oxford: Oxford University Press.

Innis, H. 1930. The Fur Trade in Canada: An Introduction to Canadian Economic History. New Haven: Yale University Press.

Jackson, W. 1997. "Becoming Native to this Place." In People, Land, and Community. H. Hannum (ed.). New Haven: Yale University Press, pp. 154-167.

Kloppenburg, J. Jr. 1988. First the Seed: The Political Economy of Plant Biotechnology. Cambridge: Cambridge University Press. 


\section{Healing the Metabolic Rift between Farming and the Eco-system: \\ Challenges Facing Organic Farmers in Canada and in Sweden}

Lawrence, G. 1990. "Agricultural Restructuring and Rural Social Change in Australia.” In Rural Restructuring: Global Processes and Their Responses. T. Marsden, P. Lowe and S. Whetmore (eds). London: David Fulton Publishers, pp. 117-143.

Laxer, G. 1988. Open for Business: The Roots of Foreign Ownership in Canada. Toronto: Oxford University Press.

Lotter, D. 2003. "Organic Agriculture.” Journal of Sustainable Agriculture, Vol. 21, No.4, pp. 59-128.

Lyson, T. 2004. Civic Agriculture: Reconnecting Farm, Food, and Community. Medford, Mass: Tufts University Press.

MacRae, R., S. Hill, J. Henning, and A. Bentley. 1990. "Policies, Programs, and Regulations to Support the Transition to Sustainable Agriculture in Canada." American Journal of Alternative Agriculture, Vol. 5, No. 2, pp. 76-92.

MacRae, R., J.Henning, and S. Hill. 1993. "Strategies to Overcome Barriers to the Development of Sustainable Agriculture in Canada: The Role of Agribusiness." Journal of Agricultural and Environmental Ethic, Vol. 6, No. 1, pp. 21-51.

Magdoff, F., Foster, J.B., and F. Buttel. 2000. "An Overview" In Hungry for Profit: The Agribusiness Threat to Farmers, Food, and the Environment. F. Magdoff, J. Bellamy Foster and F. Buttel (eds.). New York: Monthly Review, pp. 7-21.

Mann, S. and J. Dickinson. 1978. "Obstacles to the Development of a Capitalist Agriculture.” Journal of Peasant Studies, Vol. 5, pp. 466-481.

Marchak, P. 1985. "Canadian Political Economy." The Canadian Review of Sociology and Anthropology, Vol. 22, No. 5, pp. 673-709.

Marx, K. 1978. "The Eighteenth Brumaire of Louis Bonaparte.” In The Marx-Engels Reader. R. Tucker (ed.). New York: W.W. Norton and Co.

Marx, K. 1977. Capital: Volume One (translated by Ben Fowkes). Toronto: Random House Inc.

McLaughlin,D. 2000. "Escaping the Treadmill?: An Ethnographic Look at the Development of Sustainable Agriculture in Canada and in Sweden." PhD. Thesis. Fredericton, N. B.: University of New Brunswick. 
McLaughlin, M. 2002. World Food Security: A Catholic View of Food Policy in the New Millennium. Washington: Centre of Concern.

Mies, M. and V. Shiva. 1993. “The White Man's Dilemma: His Search for What he has Destroyed." In. Ecofeminism. M. Mies and V. Shiva (eds.). Halifax: Fernwood, pp. 132-163.

Mooney, P. 1988. My own Boss? Class, Rationality, and the Family Farm. Boulder Colorado: Westview Press.

Murphy, T. 1990. "From Family Farm to Capitalist Agriculture: Food Production, Agribusiness and the State." In Restructuring and Resistance: Perspectives from Atlantic Canada. B. Fairely, C. Leys, and J. Sacouman (eds.). Toronto: Garamond Press.

Murphy, R. 1994. "The Sociological Construction of Science without Nature." Sociology: The Journal of the British Sociological Association, Vol. 28, No. 4, pp. 957-974.

Northwest Area Foundation. 1994. The Economic, Environmental, and Social Impact of Sustainable Agriculture. St Paul, Minnesota: Northwest Area Foundation.

Organic Agriculture Centre of Canada. 2007. "The Vision of the Organic Agriculture Centre of Canada.” www.organicagcentre.ca/mission_stat.asp (accessed Jan. 1, 2007).

Oxfam. 2003. "Knowledge, Copyright and Patents: Intellectual Property and the Knowledge Gap." In Another World is Possible: Popular Alternatives to Globalization at the World Social Forum. W. Fisher and T. Ponniah (eds.). Halifax: Fernwood Publishing Ltd., pp. 136-143.

Ponting, C. 1991. A Green History of the World: The Environment and the Collapse of Great Civilization. New York: St. Martins Press.

Redman, C. 2004. "Environmental Degradation and Early Mesopotamian Civilization." In The Archaeology of Global Change. C. Redman, S.R. James, P. Fish, J.D. Rogers (eds.). Washington: Smithsonian Books, pp. 158-164.

Sundås, S. 1996. “Konferens Ekologiskt lantbruk.” Ekologiskt lantbruk. Uppsala . No. 3, pp. 3-5. 
Scott, J. 1998. Seeing Like a State: How Certain Schemes to Improve the Human Condition have Failed. New Haven: Yale University Press.

Steger, M. 2003. Globalization: A Very Short Introduction. Oxford: Oxford University Press.

Shiva, V. 1991. The Violence of the Green Revolution. London: Zed Books.

Smith, D. 1987. The Everyday World as Problematic: A Feminist Sociology. Toronto: University of Toronto Press.

Tainter, J. 1988. The Collapse of Complex Societies. Cambridge: Cambridge University Press.

Tong, R. 1998. Feminist Thought: A More Comprehensive Introduction (2nd edition). Boulder, Colorado: Westview Press.

Vail, D., K.P. Hasund, and L. Drake. 1994. The Greening of Agricultural Policy in Industrial Societies. Ithaca: Cornell University Press.

Wackernagel, M. and W. Rees. 1996. Our Ecological Footprint: Reducing Human Impact on the Earth. Gabriola Island, BC: New Society.

Wolf, S. and S. Wood. 1997. "Precision Farming: Environmental Legitimation, Commodification of Information, and Industrial Coordination.” Rural Sociology, Vol. 62, No. 2, pp. 180-206.

Wright, R. 2004. A Short History of Progress. Toronto: House of Anansi Press Inc. 